\title{
Virtual Proctoring In Distance Education: An Open-Source Solution
}

Chris Rose, Technology Research Institute of Florida, Inc., USA

\begin{abstract}
Students will cheat during exams, that is nothing new, but now that the Higher Education Act requires the proctoring of exams, distance education institutions now find that both they and their students have a major problem. Exams have to be proctored, but requiring distance education students to search out a reliable proctor and travel to a specific location perhaps multiple times per term imposes an undue burden on the students. But schools now have to ensure the integrity of the exam-taking process and this will require creative solutions since many distance education institutions have no physical campus and perhaps will never actually see any of their students. Virtual proctoring, whereby the student can be at their home or office and can be viewed, recorded and supervised is one solution and this will become an increasingly important part of the educational experience since the proctoring of exams is now mandatory.
\end{abstract}

\section{INTRODUCTION}

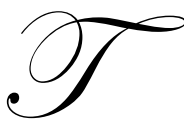

he top business schools in the country are in a quandary while they wait to find out if any of their students used a test prep site to look at the business school admissions exam. On June 23, 2008 the Graduate Management Admissions Council (GMAC) announced that they had won a court judgment against a web site scoretop.com. GMAC was awarded \$2.3 million, plus legal costs and subsequently they were able to seize Scoretop's domain name, and a computer hard drive which had payment information and other data of about 6,000 names of persons who had paid at least $\$ 30$ for a subscription to this web site (Mintz, 2008).

Not only are there instances of for-profit commercial cheating but students also attempt to abuse the system on their own. For example:

- 11 nursing students were caught cheating on a comprehensive examination and weren't allowed to graduate with their class (AP, 2008).

- Wireless earpieces based on Bluetooth technology are being used to cheat during British citizenship exams amid widespread abuse of the testing system (Quinn, 2008).

- $\quad$ Authorities in East China caught a students cheating in the national entrance exam. They used high-tech radio transmitters and receivers but the cheating was discovered when a surveillance patrol vehicle picked up radio transmissions near where the exams were being held (Xinhuanet.com, 2008).

- A graduate student drew a pistol and fired after a proctor caught him cheating during an examination at the University of Karachi The student was cheating from his text book at an examination center, when the proctor confronted him, asking for his answer sheet and cheating material. The student drew out a pistol and fled while firing in the air (Daily Times, 2008).

We cannot deny the fact that cheating is widespread in academic institutions, but the perception exists, perhaps unfairly, that this is even more of a problem in distance education academic institutions where the student might never actually be seen in person by any member of the academic staff and who sit exams remotely, usually unsupervised. 


\section{PROCTORING}

An article in the Chronicle of Higher Education was the first time many distance education institutions became aware of a requirement that soon became law. It stated "Tucked away in a 1,200-page bill now in Congress is a small paragraph that could lead distance-education institutions to require spy cameras in their students' homes. It sounds Orwellian, but the paragraph — part of legislation renewing the Higher Education Act — is all but assured of becoming law by the fall. No one in Congress objects to it. The paragraph is actually about clamping down on cheating. It says that an institution that offers an online program must prove that an enrolled student is the same person who does the work." (Foster, A. 2008).

The House and Senate conferees agreed to the language and approved this Act and it was passed in July. The House bill (H.R. 4137), known as the College Opportunity and Affordability Act, has included as a under Part H - Program Integrity SEC. 495. Recognition of Accrediting Agency or Association.

"(ii) the agency or association requires an institution that offers distance education or correspondence education to have processes through which the institution establishes that the student who registers in a distance education or correspondence education course or program is the same student who participates in and completes the program and receives the academic credit".

However, although this requirement was formally introduced into law it was nothing new to some distance education institutions since for some time it has been a stipulation of some of the accrediting bodies as a requirement for accreditation. For example, the Distance Education and Training Council (DETC) in Section 4 Part 9, asks of the institution to "Describe the procedures for proctoring examinations. Provide instructions to proctors in EXHIBIT 22." (DETC, 2008).

\section{WHY DISTANCE EDUCATION}

Proctoring is now the law but students opt for distance education because they want convenience. Requiring these students to be supervised while sitting their exams would remove some of the greatest incentives for attending a distance education institution, namely the convenience of working on your own schedule and at your own location. In fact, requiring that exams be proctored and requiring students to travel to a specific location, perhaps multiple times per term, to have their exams supervised would be a major disincentive for attending a distance education institution.

Virtual proctoring seeks to solve this dilemma and would allow students to sit exams at their home or office, using a computer and a high-speed Internet connection. Virtual proctoring should provide similar or superior security of the exam, including identification and authentication of the student, to what can be accomplished with a live proctor while offering the convenience of sitting the exam at the time and place of their choosing. Virtual proctoring can be accomplished with biometric identification and authentication, video conferencing and a content management system that can control the time, date, type and length of the exam.

\section{CURRENT SYSTEMS}

There are currently three popular systems on the market that attempts to manage virtual proctoring:

\section{Securexam}

Securexam Remote Proctor is a relatively large device which has a ball looking like a Christmas tree ornament which plugs into a standard port on a home computer. It has a place for a fingerprint scanner, a tiny microphone, and a camera. The ball gives a 360-degree view around the user and the camera and microphone records the student during exams, and anything suspicious even another voice in the room is flagged for later examination. The student sits in front of the computer and places a finger on the reader to get access to their exam. The student's fingerprint and image is matched to what was provided when they registered and then the exam is made available but controlled by a content management system. Additionally, a software application prevents the 
student from viewing anything else online, such as e-mail or retrieving files. This system costs the student $\$ 150$ and only works with Windows and Internet Explorer.

"Software Secure Inc., based in Cambridge, Mass., developed the device with \$1.1-million in seed money from Troy. In return, the university gets the first 10,000 Securexams that the company produces. If it sells more than that, the university receives a share of the proceeds" (Foster, 2008).

\section{Webassessor}

Webassessor uses actual proctors, combined with web cameras, and special software that recognizes typing styles and differentiates between such things as the speed of typing and whether the user pauses between certain letters. Students have to purchase cameras for between $\$ 50$ to $\$ 80$ apiece and this allows the live proctors to view the student's face, keyboard, and surroundings.

This system is provided by Kryterion, Inc. of Phoenix, Arizona and uses proctors that supervise up to 50 students at a time. The proctors are able to both view and listen to the students and the special keystroke software will prevent a student from sitting an exam if the pattern does not fit the sample provided at registration and the proctor can stop a student from completing an exam if they believe the student is acting suspiciously. This software is expensive and Kryterion charges $\$ 20,000$ to customize the software and for training and in addition, each time a student sits an exam it charges the school.

\section{Acxiom Corporation}

The system from Acxiom Corporation of Little Rock, Arkansas, relies completely on the person taking the test answering a number of detailed personal questions which are gathered from a number of databases such as property records and criminal records and if the student is able to answer these questions correctly they are able to take the exams.

\section{WEAKNESSES}

All of the above systems suffer from shortcomings the most obvious one being cost, since it places the mandatory requirement of proctoring out of the reach of many small academic institutions. It is doubtful that many schools would be able to afford millions of dollars to fund research for similar software to Secure Software or even an initial $\$ 20,000$ plus recurring charges for Kryterion. As far as the security of the process is concerned, there is also an inherent weakness in keystroke software, especially if the type of exam that is being proctored is, for example, a programming exam which requires very erratic keystrokes. As for Acxiom's technology, it is readily apparent that a spouse or sibling would have access to all the personal data of the student including credit records, criminal records, work history etc.

\section{THE TECHNOLOGIES}

None of these technologies that are used in these virtual proctoring systems are unique; in fact all of them are used extensively, but perhaps for other purposes. However, it is the combination of these technologies which creates the value proposition which these companies are marketing. Basically, they are just a combination of a web camera, a microphone, a fingerprint reader, a content management system and streaming audio and video.

Web cameras are ubiquitous today and many can be had (with microphone) for under $\$ 20$ and in fact, most new notebook computers come with a built-in digital web camera and microphone. Fingerprint readers are also being built into most notebook computers and for desktop computers there are many brands of fingerprint readers which plug into the standard USB port. These fingerprint readers are usually used as a means of identification either for access to the computer or as a means of access to web sites in place of typed passwords. Microsoft's fingerprint reader, which is often on sale for under \$20, has very tight integration between Internet Explorer and the user's passwords and allows the user to use a finger on the reader instead of typing their password. This is especially useful if the user has multiple passwords and actually aids security since the user will not be tempted to reuse the same 
password on multiple sites and can instead use strong passwords which they no longer have to remember.

Keystroke software is readily available from many commercial sources and there are dozens of open-source keystroke logging software applications of the market and although these are made for secretly capturing the keystrokes entered into a computer, nothing would prevent it from being modified to allow it to capture then compare keystrokes. However, keystrokes suffer from the inherent deficiency of not being very effective during certain types of exams which do not have constant keystrokes and should not be considered as an ideal solution for identification and authentication. It is not and can never be as effective as any other basic biometric solutions such as fingerprints or retina scans. There are multiple content management systems on the market from the very popular (and expensive) Blackboard to the open-source and freely available Moodle. All these systems have the ability to authenticate the users through passwords and to limit content to a certain date and a specific length of time.

Streaming audio and video requires a dedicated server since no shared hosting company will allow streaming media servers in a shared web hosting environment. The most economical method of overcoming this hurdle would be to utilize Virtual Private Servers (VPS). VPS is simply a more expensive type of shared hosting but it is shared among less users and each user sharing this type of service has access to the root directory so the server appears as if it is a dedicated server. Using VPS, a streaming media server can be deployed to support streaming audio and video. To make live video possible then on this streaming video software it is necessary to have a type of web conferencing application, some popular versions are heavily advertised, such as Go to Meeting and WebEx.

\section{OPEN SOURCE}

Small distance education academic institutions can meet these new requirements by the skillful utilization and combination of freely available open-source applications on the market and with a little effort can create their own virtual proctoring system.

To be able to biometrically identify the student the starting point would be a readily available fingerprint reader, such as the Microsoft fingerprint reader which is available in Office Depot, Staples or online at Amazon.com or many other places. This fingerprint reader plugs into a standard USB port but the most complicated part of implementing this technology is the actual identification and authentication of the student using the fingerprint reader since the Microsoft fingerprint reader was not designed for the purpose of matching one fingerprint against a database of fingerprints and then giving access to a network. However, using just the hardware and without installing the Microsoft drivers and with sufficient coding skills, a Java applet can be created which will control the reader and allow the matching of fingerprints thereby creating a proper identification system.

Once the ability to match fingerprints is developed then the second hurdle is access control. Access control is easily managed by using a content management system, the most popular open-source system being Moodle and this will control the date and length of the exam. If the authentication application is properly created, Moodle and the fingerprint reader for identification and authentication must work together. The Java applet has to be embedded in the Moodle login page which means that the application will combine the user name and password from Moodle and the biometrics from the fingerprint reader for strong identification and authentication. If any one of these three (the username, password or fingerprint) fails then the user is not allow to enter the web site to sit the exam. Once inside the web site then Moodle controls access to the exam by allowing the exam to be visible on a certain day and for a specific amount of time if needed.

The third aspect of this system is the visual monitoring and recording of the student and this would require that the students purchase a standard web cam, if one is not already included with their computer. The preference here is to one which has a built-in microphone since this will allow the proctor to not only see the student while they sit the exam but also to hear and record any sound. To run streaming media necessitates the installation of streaming media server software and there are many proprietary (and expensive) server applications for streaming media but a reliable and popular open-source solution is Red5. For the web conferencing application that will run on Red5, OpenMeetings is popular, but as stated, it needs to run either on a dedicated streaming media server or on a VPS. With Red5 and OpenMeetings, the student can be viewed and both the audio and the video recorded for future analysis, if required. 


\section{TRloF fingerprint login}

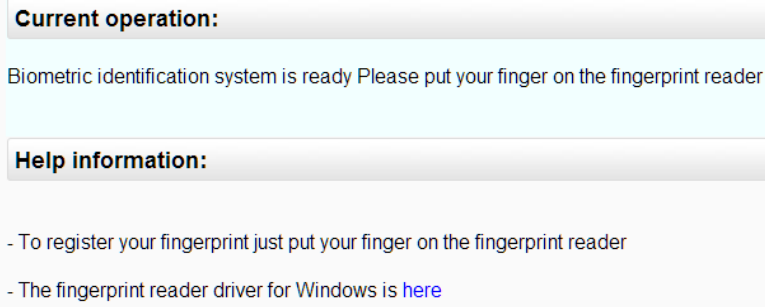

Figure 1: Fingerprint registration screen

\section{THE PROCESS}

The entire process of this virtual proctoring system has to happen is a specific sequence since this system is not a comprehensive proctoring system specifically made for the purpose but rather was patched together to produce the required result.

First the student needs to connect their Microsoft fingerprint reader and download special drivers to enable the fingerprint reader to perform the function of matching fingerprints. Once this is done the next step would be to $\log$ into OpenMeetings with a supplied username. Once in OpenMeetings the proctor will be able to see the student and the student will also be able to see their own video image. This can be used as an opportunity for the student to adjust their camera so that it is properly focused. At this point the proctor and student can communicate either with voice or using the built-in messaging system but the proctor should now be able to see and hear the student and record them for the next step.

The next step would entail the student minimizing OpenMeetings and logging on to Moodle with their same supplied username to register their fingerprint since access to the exam will not be granted until the user is authenticated. This initial registration of the fingerprint is ideally done some time before the student is actually ready to sit the exam. The proctor will be able to see the student placing their finger on the fingerprint reader and record them while doing this so that a record of the image of the student should now match the fingerprint which should now match the username.

\section{TRloF fingerprint login}

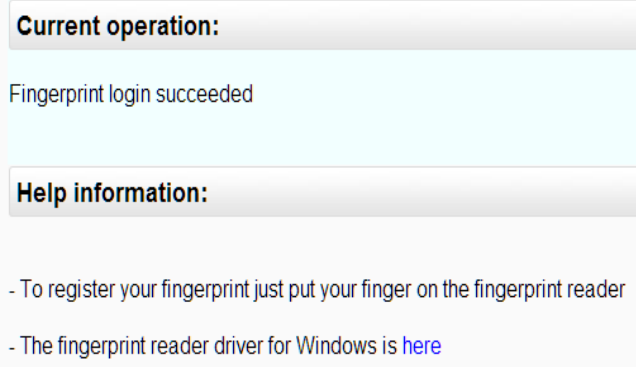

Figure 2: Fingerprint match successful 
On the day of the exam the student would first log unto OpenMeetings with their username, adjust their camera and when directed, proceed to Moodle. At Moodle they will again enter their username, place their finger on the reader and if it is a match they will be able to see the exam for which they have been registered. Once in the exam space, Moodle will control all aspects of the exam, including the type of questions, if the results are immediately available, if it is timed, if the student is allowed more than one attempt etc. In each OpenMeetings conference room, the proctor will be able to supervise and monitor up to 15 students at a time. Moodle has no user limits so multiple simultaneous instances of OpenMeetings may be required at a time, the only technical limitation being the robustness of the Red5 server and the amount of available bandwidth.

One more layer of security can be added to this exam process and this is to prevent the student from accessing any other application on their computer, such as notes, email, pdf files etc. This can be accomplished by using a Java applet which fills up the entire computer screen area and which only allows certain applications and web sites to be accessed. Again, this is not a very difficult application and is easily done with a little creative programming.

This system will work with any high-speed Internet connection and in fact, if the student only has a dial-up connection it is still possible to provide identification and authentication for exams through the fingerprint matching system but the video monitoring system would not have sufficient bandwidth to work efficiently.

\section{CONCLUSION}

The proctoring of exams is now a requirement but many small distance education academic institutions are going to find it extremely difficult to fulfill the requirement of the law mainly because of cost. Many of the virtual proctoring systems that are currently available are expensive and would place an undue burden on these small schools. The alternative would be to force these distance education students to find a proctor and then travel to that proctor on a specific day and time to sit the exam so that the exam can be certified by the proctor. This however, is contrary to what students have come to expect from distance education and many would be reluctant to give up their freedom and convenience of choosing the time and place to sit exams.

However, all is not lost as small distance education schools can utilize freely available products and opensource software to create their own virtual proctoring system. By using a combination of a fingerprint reader, a content management system and streaming media, the student can be properly identified and recorded while they sit their exams thereby fulfilling the requirement of the Higher Education Act.

\section{REFERENCES}

1. Associated Press. Prairie View says 11 nursing students caught cheating - Dallas Morning News 05/29/2008 http://www.dallasnews.com/sharedcontent/APStories/stories/D90V2CVO0.html . Retrieved August 15, 2008

2. Chinaview.cn. Official seized for cheating fraud in China's college exam. Chinaview.cn June 30, 2008 http://news.xinhuanet.com/english/2008-06/30/content 8466048.htm . Retrieved August 15, 2008.

3. Distance Education and Training Council (DETC) Guide to Self-Evaluation Report, Section 4 Part 9, 2008.

4. Dailytimes. Student opens fire after caught cheating. Dailytimes.com June 14, 2008 http://www.dailytimes.com.pk/default.asp?page=2008106\14/story 14-6-2008_pg12_6. Retrieved August $15,2008$.

5. Foster, A. New Systems Keep a Close Eye on Online Students at Home, Chronicle of Higher Education Volume 54, Issue 46, Page A1, July 25,2008

6. Levy F. \& Lawyue M. GMAT Scandal Has MBA Students Sweating. Users of the shuttered GMAT test prep site Scoretop are worried about penalties. http://www.businessweek.com/bschools/content/jul2008/bs2008071_278439.htm?chan=top+news_top+ne ws+index_news+\%2B+analysis. Retrieved August 15, 2008.

7. Mehta, S. Testing group reveals why it voided AP exams of about 400 students at O.C. high school Los Angeles Times, July 24, 2008. http://www.latimes.com/news/education/la-me-trabuco242008jul24,0,6014463. story Retrieved August 15, 2008 
8. Mintz, P. Business Schools Mull Scandal Options. Business Week. July 13, 2008

http://www.businessweek.com/bschools/content/jul2008/bs20080713 728550.htm?chan=top+news top+ne ws+index business+schools Retrieved August 15, 2008.

9. Moodle http://moodle.org/

10. OpenMeetings http://code.google.com/p/openmeetings/

11. Quinn, B. Citizenship answers sent via Bluetooth . June 15, 2008.The Guardian http://www.guardian.co.uk/technology/2008/jun/15/mobilephones.britishidentity Retrieved August 15, 2008.

12. Red5 http://osflash.org/red5

13. Riviera, C. Cheating on ACT, SAT college entrance exams has few consequences. Los Angeles Times. July 14, 2008 http://www.latimes.com/news/local/la-me-cheat14-2008jul14,0,963372.story. Retrieved August 15, 2008.

14. Xinhuanet.com High-tech exam cheat caught using radios in E China. Xinhuanet.com July 6, 2008. http://news.xinhuanet.com/english/2008-07/06/content_8498856.htm Retrieved August 15, 2008. 
NOTES 